\title{
REPRESENTAÇÕES SOCIAIS SOBRE CRIANÇA E SER PROFESSORA DE CRIANÇAS POR ALUNAS DO CURSO DE PEDAGOGIADA UFMS E UNESP
}

\author{
SOCIAL REPRESENTATIONS ABOUT CHILDREN AND BEING \\ NURSERY SCHOOL TEACHERS HELD BY PEDAGOGY \\ UNDERGRADUATES FROM UFMS AND UNESP
}

\author{
Sílvia Adriana Rodrigues* \\ Célia Maria Guimarães ${ }^{* *}$ \\ Claudia Cristina Garcia Piffer ${ }^{* * *}$
}

\begin{abstract}
Resumo
Este texto apresenta os resultados preliminares de uma pesquisa em andamento que, tendo como aporte teórico a Teoria das Representações Sociais, de Moscovici, investiga a interferência dos processos de formação inicial nas representações que os alunos de dois cursos de Pedagogia distintos têm e constroem sobre o trabalho pedagógico na Educação Infantil (EI). O estudo, de caráter longitudinal, acompanha os estudantes em seu processo de formação inicial, em curso de 2009 a 2012, adotando questionários e entrevistas como instrumentos para a obtenção dos dados. Assim, neste artigo nos deteremos na análise de representações sobre criança e o que é e como é ser professor da Educação Infantil. Os dados não indicam elaborações sobre o que é e como é ser professor de crianças pequenas, tampouco sobre a especificidade do trabalho pedagógico na El, permitindo-nos afirmar que em ambos os grupos o uso dos termos professor e criança refere-se ao trabalho desenvolvido no Ensino Fundamental.

Palavras-chave: Representações sociais. Educação Infantil. Formação de professores.
\end{abstract}

\begin{abstract}
This text presents the preliminary results of an ongoing research that, based on Moscovici's Social Representation Theory, investigates the interference of initial training processes in the representations that students from two different courses of Education has and build about the pedagogical work in Nursery Education (NE). The study is longitudinal in nature and accompanies the students in their initial training process, from 2009 to 2012, using questionnaires and interviews as data collection tools. Thus, in this article we will consider the analysis of representations about children and what it is and how it is to be a nursery education teacher. The data indicate no elaboration on what it is and how it is to be a teacher of young children, nor on the specificity of the educational work in NE, allowing us to state that in both groups the use of the terms teacher and child is related to the work developed in Primary Education.
\end{abstract}

Keywords: Social representations. Nursery education. Teacher training.

\section{Introdução}

O trabalho ora apresentado é substrato de um estudo em desenvolvimento com o objetivo de investigar as representações sociais - RS de alunos sobre o trabalho do professor da Educação Infantil. Buscamos também investigar se as representações de professoras ${ }^{1}$ de crianças menores estão contem-

\footnotetext{
*Professora da Universidade Federal do Mato Grosso do Sul. E-mail: silvia.rodrigues@ufms.br

" Professora da Universidade Estadual Paulista Júlio de Mesquita Filho - Campus de Presidente Prudente. E-mail: cmgui@fct.unesp.br

*** Professora do Departamento de Educação da Faculdade de Ciências e Tecnologia da Universidade Estadual Paulista Júlio de Mesquita Filho - Campus de Presidente Prudente.

E-mail: claudiapiffer@ig.com.br
}

pladas no perfil de professor e no modelo de educação, implícitos nas representações dos estudantes de Pedagogia.

A investigação está organizada de forma a possibilitar a comparação dos dados de duas regiões brasileiras e, ao mesmo tempo, permitir que cada um dos dois eixos investigue problemas específicos de seu interesse. O critério de escolha das universidades investigadas foi a presença de duas dentre as três pesquisadoras atuando como docentes nos cursos estudados. As universidades envolvidas, uma estadual e outra federal, são referências

\footnotetext{
${ }^{1}$ O termo professora será utilizado, ao longo do texto, considerando os resultados recorrentes nas pesquisas da área que indicam a crescente feminilização do magistério, nesse nível de ensino da Educação Básica brasileira (CAMPOS; FÜLLGRAF; WIGGERS, 2006).
} 
de formação pública em suas regiões, as quais, por sua vez, apresentam singularidades contextuais de interesse ao estudo de representações sociais.

Desenvolvida por três pesquisadoras de duas universidades de dois estados brasileiros, a pesquisa apoia-se na Teoria das Representações Sociais (RS) de Moscovici, ${ }^{2}$ na Teoria do Núcleo Central de Abric $^{3}$ e em referenciais da Educação Infantil (EI).

Pressupõe-se, neste estudo, que as funções tradicionalmente atribuídas às creches e pré-escolas e as imagens normalmente atribuídas à criança de 0 a 5 anos exercem uma função organizadora das RS do trabalho da professora de El.

A investigação conta com 107 estudantes ingressantes nos cursos de Pedagogia de universidades públicas no ano de 2009: 68 da UNESP (duas turmas) e 39 da UFMS (uma turma) ${ }^{4}$. No início do primeiro bimestre letivo referido foram realizadas a primeira etapa da investigação, a partir do uso de questionários, e a técnica de associação livre de palavras junto aos ingressantes desse mesmo ano letivo.

Assim, tendo em vista a especificidade da EI, as palavras indutoras para a técnica de associação livre foram delimitadas em seis: criança, creche, pré-escola, professor, afetividade e família. No que diz respeito ao questionário ${ }^{5}$, este foi composto por duas partes: um questionário-perfil com 23 questões, divididas em 14 questões gerais e nove específicas e um questionário-carta que contemplou aspectos como: desenvolvimento versus preparação para a escola; doméstico versus profissional; cuidado versus educação, além dos elementos que marcam a especificidade da profissão, totalizando 28 questões.

$\mathrm{Na}$ segunda etapa, ocorrida no segundo ano de curso, em novembro de 2010 , foram realizadas seis entrevistas para cada uma das três turmas investigadas, com o objetivo de obter novos dados referentes às RS em estudo, além de captar dados que permitirão, em momento posterior, verificar se o estágio curricular obrigatório alterou algum aspecto

\footnotetext{
${ }^{2} \mathrm{O}$ conceito de representação social, segundo o modelo teórico unitário de Moscovici (1978, 1984a, 1981), designa uma forma de conhecimento específico, o saber do senso-comum, cujos conteúdos manifestam a operação dos processos geradores e funcionais socialmente caracterizados. (GUIMARÃES, 2005).

${ }^{3}$ A teoria do núcleo central, segundo Abric (1994), propõe que "toda" representação se organiza em torno de um núcleo central. É ele quem determina a significação da representação e sua organização interna. É um subconjunto da representação e composto de um ou alguns elementos. São esses elementos que desestruturam ou dão significação totalmente diversa à representação. (GUIMARÃES, 2005).

${ }^{4}$ Siglas: UNESP - Universidade Estadual Paulista; UFMS - Universidade Federal do Mato Grosso do Sul.

${ }^{5}$ Trabalho realizado a partir de questionário similar elaborado pelas professoras Maria Helena Cordeiro, da Universidade do Vale do Itajaí - UNIVALI, e Lenira Haddad, da UFAL, no ano de 2008.
}

das RS dos estudantes. O procedimento se deu a partir de roteiro semiestruturado composto por 28 questões.

\section{Pressupostos teóricos: abordagens consideradas no estudo}

Nos últimos anos do século $X X$ e anos iniciais do século $X X I$ a concepção de infância e de criança, no Brasil, não sofreu alterações significativas no cotidiano das instituições de El. Ocorreu diferentemente em relação ao ordenamento legal, que, de uma visão de criança carente, passiva e incapaz, evoluiu para a concepção de sujeito de direitos, direitos amplamente assegurados na Constituição Federal de 1988 (art. $7^{\circ}$, XXV e 208, IV), na Lei de Diretrizes e Bases da Educação Nacional - LDB (Lei $n^{\circ}$ 9.394/1996), no Estatuto da Criança e do Adolescente - ECA (Lei $n^{\circ}$ 8.069/1990) e no Plano Nacional de Educação - PNE (Lei n 10.172/2001).

A LDB 9.394/96, ao inserir as creches e pré-escolas no sistema de ensino oficial, gerou a necessidade da formação específica do professor da $\mathrm{El}$, além de salientar que o atendimento prestado à criança na instituição de EI (IEI), na modalidade creche e pré-escola, exige a articulação entre a educação da criança e os seus cuidados. Tal afirmação nos remete imediatamente para o problema do papel social dessa instituição, o qual se encontra ainda hoje em processo de (in)definição, reforçada pelo distanciamento entre o que preconiza a legislação e as ações cotidianas. A pesquisa realizada por Campos, Füllgraf e Wiggers (2006) detectou esse quadro. Cerisara, Candal Rocha e Silva Filho (2007, p. 6) enfatizam que:

\begin{abstract}
Afirmar que a creche e a pré-escola, além de desempenharem um papel social específico na sociedade industrial contemporânea, definem-se por ser um local onde deve prevalecer a intencionalidade e a sistematização do trabalho realizado junto à criança, parece estar longe de configurar-se como um consenso e uma obviedade. A necessidade de caracterização deste espaço educativo e a definição de critérios mínimos para o atendimento prestado às crianças na faixa etária de 0 a 6 anos permanecem como desafios.
\end{abstract}

O processo de transformação da função da instituição de Educação Infantil nos últimos anos foi impulsionado pela construção da concepção de criança como sujeito de direitos, do direito à Educação Infantil amplamente assegurado pelo ordenamento legal. Relativamente a esse direito, impõe-se um atendimento infantil que integre as duas funções - cuidar e educar - exigindo que "[...] o adulto que atua na área seja reconhecido como um profissional. Isto implica que lhe devem 
ser assegurados condições de trabalho, plano de carreira, salário e formação continuada condizentes com seu papel profissional." (CERISARA, 1996, p. 19).

Nessa perspectiva, os projetos de formação inicial de professores para El devem ser capazes de articular processos, estratégias e práticas, de tal maneira que os futuros professores compreendam a Pedagogia que responde à integração dos cuidados à educação da criança, enquanto aprendem a realizá-la, tendo como referência a importância das interações sociais (MACHADO, 2000). A formação precisa favorecer a elaboração dos conhecimentos legais, teóricos, e o exercício prático (estágios; estudos de casos; oficinas pedagógicas, trabalhos de campo etc.), para que o professor saiba como organizar ambientes interativos numa Pedagogia voltada para os relacionamentos, na qual a participação da criança é valorizada e incentivada mediante propostas em que o exercício da capacidade de comunicação, expressão e representação são os aspectos-chave. Além disso, a formação inicial deve orientar-se para a capacidade de elaboração de propostas pedagógico-curriculares com identidade própria, plenas de referenciais teóricos e práticos que traduzam a compreensão da amplitude do respeito aos direitos da criança, seja na creche, seja na pré-escola.

Machado (1999) continua a defesa da necessidade de delimitação da especificidade do espaço educativo da El (creche/pré-escola) e explicitação de seus pressupostos. Para isso, aponta a busca de sustentação em aportes teóricos fundamentados nas necessidades e características de crescimento e desenvolvimento das crianças pequenas.

Nesta pesquisa, inspiradas pelas argumentações anteriores, consideramos que a abordagem das representações sociais durante o processo formativo de professores de crianças pequenas favorece a construção da identidade de professora de crianças pequenas - profissional daquele ambiente educativo diverso da casa - por meio da compreensão de como o futuro professor (des)constrói crenças, elabora saberes e articula a identidade profissional específica.

As representações sociais, suas ideias-imagens do trabalho pedagógico, as expectativas elaboradas sobre o que/como é ser professora de crianças pequenas, na creche e na pré-escola, condicionarão escolhas éticas, pedagógicas e as interações.

Baillauquès (2001) ressalta que resultados de estudos tendem a demonstrar que considerar as representações sociais contribui para a profissionalização docente, no percurso de sua evolução. Explica que trabalhar com as representações serve primeiramente para sensibilizar em relação ao trabalho docente, reconhecer suas motivações, tendo como referência sua adequação à realidade profissional, aos espaços onde exercerá a docência. No processo de formação, esse primeiro processo de reflexão é seguido de discussões e, posteriormente, de contatos com o lócus de trabalho com crianças pequenas e teorizações em sala de aula, na universidade.

Outro aspecto apontado pela autora, em continuidade ao exposto antes, é a possibilidade de realizar um trabalho de proximidade entre as imagens, as expectativas do trabalho docente e as suas realidades, pois, se assim for, o aluno-estagiário poderá fazer avaliações em relação aos próprios saberes, ao saber-fazer e às atitudes exigidas pelo trabalho docente.

Desse modo, o praticante poderia tornar-se, na melhor das hipóteses, um criador de seu trabalho, de seus progressos, de seu posicionamento e de suas posturas pessoais dentro da profissão visada, para si mesmo e para o outro. Isto se daria em seu contexto de normas, regras, dispositivos e ambientes. Ele participaria da elaboração psicossocial do papel, atingindo, assim, sua própria concepção deste último, com a projeção de si mesmo nessa abordagem. (BAILLAUQUĖS, 2001, p. 52).

De acordo com Moscovici (1978, 1984b, 2003), as RS são elaborações psicológicas e sociais, construídas pelos indivíduos e com os indivíduos, e possuem uma dupla função: tornar familiar o que é estranho/ameaçador e perceptível o que é invisível. É o conhecimento habitualmente denominado espontâneo, ingênuo, vulgar, do senso comum ou pensamento natural, por oposição ao pensamento científico. A esse tipo de conhecimento, Guimarães (2005) chama de conhecimento prático. Acrescenta que ele se constitui com fundamento em nossas experiências, nas informações, conhecimentos e modelos de pensamento recebidos e transmitidos por intermédio da cultura, da educação e da comunicação social.

Nesse sentido, as RS explicitam como um grupo se relaciona com um dado objeto social, servem de guia de ação, orientam a comunicação e a relação com o mundo e os outros. Também oferecem referências para interpretação da realidade e favorecem a construção de valores, necessidades, interesses de um mesmo grupo. O conhecimento apreendido do objeto passa a fazer parte das conversas e aparece na forma de frases, visões, jargões, ditados, preconceitos, estereótipos, soluções etc., tendo um efeito de realidade para o indivíduo (GUIMARÃES, 2000).

Depreende-se que investigar, no decorrer da formação inicial, as RS que os futuros professores de crianças pequenas têm, bem como suas transformações e/ou permanências, poderá nos orientar na escolha de processos 
que verdadeiramente nos permitam contribuir, como formadores, para a elaboração de outra compreensão da criança pequena e da função da professora, a partir da revisão das crenças sobre a creche/pré-escola e da função da creche e préescola em vigor.

No Brasil, a Lei de Diretrizes e Bases da Educação Nacional, Lei no. 9.394/96, redefine creche e pré-escola de maneira a se diferenciarem apenas quanto à idade atendida, 0 a 3 anos, e 4 a 5 anos, respectivamente, devendo ambas voltar-se às ações de cuidar e educar, em período parcial ou integral. No entanto, essas conquistas são recentes e não pertencem ao senso comum. O pressuposto básico deste estudo é que as funções tradicionalmente atribuídas às creches e pré-escolas exercem uma função organizadora das RS de trabalho da professora de El, afetando as imagens que os estudantes de Pedagogia vêm construindo sobre o trabalho desse profissional.

Levando em conta o contexto de definição de contornos de um novo perfil profissional para um campo que ainda busca firmar sua identidade, a pesquisa colabora para uma melhor compreensão da estrutura e dinâmica das representações sociais que condicionam e muitas vezes limitam a ação do(a)s profissionais de El. Pretende-se contribuir na definição de políticas públicas para a formação de professores para a El, que considerem a especificidade dessa etapa da Educação Básica, particularmente sua dupla função social e educacional, e as peculiaridades de uma ação educativa voltada ao grupo etário de crianças de 0 a 5 anos.

\section{As representações sociais dos estudantes sobre criança e ser professor(a) de crianças pequenas}

A opção metodológica desta investigação se fundamenta numa abordagem qualitativa e propõe um estudo longitudinal. Pretende-se acompanhar os estudantes entre os anos de 2009 e 2012, período da sua formação inicial, com o intuito de conhecer as RS sobre criança e professora de crianças pequenas que os estudantes em formação podem ter, em diferentes momentos de sua graduação. Teremos em vista os conhecimentos que detinham previamente ao processo de formação inicial e as transformação/mudanças conseguidas, no decorrer e ao final do processo.

Os resultados em discussão foram obtidos por meio do tratamento das respostas no programa EVOC 2002 (Ensemble de Programmes Permettant L'annalyse des Evocations, de Vergès) para as questões de associação livre com as palavras indutoras
- professor e criança. Orientada pela abordagem estrutural de estudos de Representações Sociais, a análise dos dados priorizou, por meio do citado software, a identificação dos conteúdos e da estrutura da representação social. Para o tratamento das questões abertas, selecionadas do total de questões do instrumento, utilizamos o software SPSS e a técnica de análise de conteúdo (BARDIN, 1977), a qual foi utilizada também como subsídio para análise das entrevistas semiestruturadas.

Cabe salientar que as questões abertas selecionadas para este texto nos permitem examinar as preferências pelo campo de trabalho, expectativas/ satisfação e motivação pela futura profissão. A exposição que se segue nesta seção foi organizada trazendo a caracterização dos estudantes participantes, seguida da análise dos dados que apresentam o núcleo central das RS sobre criança e professor, e análise de algumas questões abertas do questionário-carta.

Assim, no que diz respeito ao perfil dos estudantes, a análise dos dados demonstrou tendências, quais sejam: a grande maioria é do sexo feminino; os estudantes da UNESP são mais jovens - a maioria tem entre 17 e 20 anos -, enquanto que metade dos alunos da UFMS se encontra nessa faixa etária e a outra metade tem entre 21 e 30 anos. Sobre a situação civil, nos dois grupos, temos a maioria de solteiros, sem filhos; em ambos os grupos, a grande maioria dos estudantes dedica-se atualmente somente a fazer o curso de graduação. Por fim, a maior parte dos estudantes dos dois grupos não tem experiência de trabalho com crianças pequenas, seja na educação formal ou informal.

Acerca das associações livres, a palavra CRIANÇA produziu 520 palavras nos 107 alunos participantes, das quais 169 foram diferentes. Para a composição do Núcleo Central (NC) e dos elementos periféricos (EP) consideramos as palavras que tiveram frequência maior que 4 e intermediária de 11 (EVOC, 2002). Com relação à ordem de evocação, foram consideradas como representações do NC as palavras com frequência maior que 10 e ordem de posição menor que 2,5.

As palavras alegria, amor, que são representativas de uma visão abstrata da criança, compuseram o NC CRIANÇA dos estudantes da FCT/ UNESP. No caso dos estudantes da CPAN/UFMS, se considerarmos a palavra brincadeira - que compôs o NC CRIANÇA -, teremos uma visão unilateral das características da criança, o que esclarece em parte a RS de professor demonstrada.

No segundo quadrante, a associação da palavra CRIANÇA com as palavras carinho e escola, feita pelos estudantes da FCT/UNESP, confirma as características e a identidade de professor 
demonstrada pelo NC. Entre os alunos da CPAN/ UFMS não foram encontradas associações para a palavra criança nesse quadrante.

Entre os estudantes da FCT/UNESP as associações menos frequentes das palavras foram o vocábulo aprendizado e brincadeiras com a palavra CRIANÇA, que confirmam o NC. As palavras mãe, pais, família demonstram a desvinculação da criança com seu grupo social primário; as palavras inocência, sinceridade e futuro, por outro lado, ao comparecerem com baixa frequência, confirmam a visão romantizada da criança, já denotada no primeiro quadrante.

No caso dos estudantes da CPAN/UFMS a palavra criança foi associada a amor, alegria, carinho, inocência e pureza, além das palavras desenvolvimento, infância e família, também reafirmando a imagem romântica e idealizada já evidenciada no primeiro quadrante.

Finalmente, os estudantes da FCT/UNESP, no último quadrante, com palavras menos frequentes e bem mais tardias nas evocações, realizaram associações com a palavra CRIANÇA que demonstraram um distanciamento tanto da visão abstrata de criança - pureza, felicidade, bagunça - como também de uma das atividades da infância (brinquedo) e de aspectos fundamentais do trabalho com a criança: cuidado, família, pai. Quanto às palavras educação e escola, relacionadas à palavra CRIANÇA, os estudantes da CPAN/ UFMS revelaram não só um distanciamento da educação formal-escolarizante, como também da educação como parte do universo infantil. A palavra feliz, citada tão tardiamente, causa estranheza porque pode estar indicando a impossibilidade de ser/estar feliz na instituição formal de educação.

Em síntese, os dois grupos organizaram sua RS em torno de uma imagem idealizada e abstrata de criança como ser em desenvolvimento, que tem como características a alegria, o amor, o carinho e a inocência, e como atividade principal e única a brincadeira. Os elementos mais periféricos da RS sobre criança demonstram uma contradição entre a imagem de criança abstrata (felicidade e bagunça) e aquela capaz (aprende), que precisa de cuidado e educação num espaço - a escola -, que nos remete à RS de professor escolar e às práticas próprias dos primeiros anos do Ensino Fundamental.

Acerca das palavras associadas ao estímulo PROFESSOR, os 68 estudantes da UNESP produziram 109 palavras diferentes para um total de 275 associações, enquanto que os 39 estudantes da UFMS produziram 77 palavras diferentes para um total de 162 associações. Percebe-se maior disper- são de associações entre os estudantes da UFMS. Para a composição do Núcleo Central (NC) e dos elementos periféricos (EP), levamos em conta as palavras que tiveram frequência maior que 4 e intermediária de 11 (EVOC, 2002). Com relação à ordem de evocação, foram consideradas como representações do NC as palavras com frequência maior que 8 e ordem média de evocação (OM) menor que 2,5.

As palavras que compuseram o provável NC PROFESSOR (Quadro 1) dos estudantes da UNESP foram: ensinar, indicando a tarefa que cabe ao professor; e escola, indicando o local onde ocorre o ensino. A atitude ou qualidade esperada daquele que ensina foi indicada pela palavra responsabilidade, e a evocação daquele que ensina na escola com responsabilidade ocorreu por meio das palavras educador e profissional.

No caso dos estudantes da UFMS, as palavras do provável NC PROFESSOR referiram-se a educador e à qualidade que este deve apresentar na relação interpessoal com a criança: amigo.

Quadro 1 - Primeiro quadrante do "quadro das quatro casas" mostrando frequência e ordem das evocações induzidas pela palavra "professor" nos grupos de estudantes da UNESP e da UFMS

\begin{tabular}{|c|c|c|c|c|c|c|}
\hline \multirow{7}{*}{ 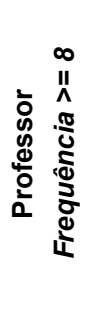 } & \multicolumn{3}{|c|}{$\begin{array}{l}\text { Primeiro quadrante-UNESP } \\
\text { (provável núcleo central) }\end{array}$} & \multicolumn{3}{|c|}{$\begin{array}{l}\text { Primeiro quadrante-UFMS } \\
\text { (provável núcleo central) }\end{array}$} \\
\hline & Evocações & $f$ & OM & Evocações & $\mathbf{F}$ & OM \\
\hline & Educador & 17 & 1,529 & Amigo & 13 & 2,462 \\
\hline & Ensinar & 20 & 2,200 & Educador & 15 & 1,333 \\
\hline & Escola & 9 & 2,222 & & & \\
\hline & Profissional & 9 & 2,222 & & & \\
\hline & Responsabilidade & 12 & 2,083 & & & \\
\hline
\end{tabular}

Fonte: Dados organizados pelos autores.

As evocações dos estudantes da UNESP demonstraram que o NC de sua RS está muito relacionado à identidade do professor dos anos iniciais do Ensino Fundamental. Os estudantes da UFMS, por sua vez, têm o que parece ser o NC de sua RS amparado na imagem do educador-amigo. A ausência de associações a outras qualidades ou aos saberes esperados no trabalho pedagógico com crianças pequenas indica uma ideia romântica e idealizada sobre ser professora de creche e pré-escola, além de se distanciar da figura do professor como profissional da área de educação. No caso da UFMS, ressaltamos que se faz necessário falar de NC com cautela devido ao número alto de palavras diferentes associadas à palavra professor.

No segundo quadrante (Quadro 2), as associações dos estudantes da UNESP evidenciaram características ou capacidades esperadas do professor: amigo, autoridade, inteligência e respeito. As associações presentes na segunda periferia indicaram uma imagem de professor que não poderia 
prescindir da profissionalidade, da sensibilidade e da ética, no trato com a criança. Entre os estudantes da UFMS, não foram encontradas associações para a palavra professor.

Quadro 2 - Segundo quadrante do "quadro das quatro casas" mostrando frequência e ordem das evocações induzidas pela palavra "professor" nos grupos de estudantes da UNESP e da UFMS

\begin{tabular}{|c|c|c|c|c|c|c|}
\hline \multirow{6}{*}{ 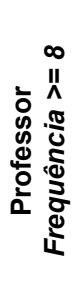 } & \multicolumn{3}{|c|}{$\begin{array}{l}\text { Segundo quadrante - UNESP } \\
\text { (elementos periféricos) }\end{array}$} & \multicolumn{3}{|c|}{$\begin{array}{l}\text { Segundo quadrante - UFMS } \\
\text { (elementos periféricos) }\end{array}$} \\
\hline & Evocações & $f$ & OM & Evocações & f & OM \\
\hline & Amigo & 10 & 2,700 & \multirow{4}{*}{\multicolumn{3}{|c|}{ Não houve }} \\
\hline & Autoridade & 10 & 2,900 & & & \\
\hline & Inteligência & 9 & 3,000 & & & \\
\hline & Respeito & 8 & 2,625 & & & \\
\hline
\end{tabular}

Fonte: Dados organizados pelos autores.

As associações mais próximas do NC (elementos periféricos) manifestadas pelos estudantes da UNESP e a ausência encontrada entre os ingressantes da UFMS nos impelem a afirmar a possível centralidade da RS apontada antes (Quadro 2).

Menos frequentes (bem menores que 10), entre os estudantes da UNESP, foram evocadas as palavras: aluno; aula (o espaço onde o educador exerce sua função); e conhecimento, formação, educar, educação (o objeto do seu trabalho). É interessante a frequência baixa para a visão de criança pequena como aluno e a menção da sala de aula como único espaço das interações com a criança. Mas não parece interessante a baixa frequência em relação ao que é próprio da profissão docente. Outras associações se dão quanto a qualidades esperadas do educador: capacitado, dedicação, mestre, preparado, sabedoria. No caso dos estudantes da UFMS, a palavra PROFESSOR foi associada com menos frequência às palavras: capacitado, dedicação, educar, educação, ensinar e responsabilidade.

Os estudantes da UFMS, ao demonstrarem as associações anteriores com menor frequência, reforçam o NC educador-amigo. Uma ocorrência que nos chama a atenção é a utilização de educador, em detrimento da palavra professor, bem como seu uso no masculino, já que a grande maioria é do sexo feminino. Compreender as razões para tal ocorrência é tarefa para etapas seguintes da pesquisa.

Finalmente, no que concerne aos estudantes da UNESP, no último quadrante, com palavras menos frequentes e bem mais tardias, encontramos aspectos relacionados à relação do adulto com a criança: amor, paciência, carinhoso, exemplo, disciplina, importante - e a palavra didática. Talvez essas evocações tardias revelem a incompreensão dos aspectos pedagógicos específicos do trabalho com crianças pequenas, justificada pela condição de ingressantes no curso, aliada ao senso-comum de que, para ser professor na creche e na pré-escola, é necessário ser amoroso, paciente, exemplar, saber controlar as crianças e ter didática, compreendida como a capacidade de "manejar" bem a turma.

Os estudantes da UFMS fizeram evocações que relacionam PROFESSOR às palavras aluno, atencioso, orientador, formador, paciência, respeito, conhecimento e profissional. Tais evocações tardias parecem confirmar, mais uma vez, o provável NC educador-amigo, mas contraditoriamente consideram aspectos relacionados à profissionalização, além de tomar a criança pequena como aluno, o que pode revelar a referência à criança e ao professor do Ensino Fundamental.

Em síntese, os estudantes da UNESP apresentaram uma tendência de organização do NC de sua RS ancorando-o no conceito de educador-profissional que ensina na escola com responsabilidade, autoridade, inteligência, amizade e respeito. Por sua vez, os estudantes da UFMS pareceram organizar o NC de sua RS em torno da ideia-imagem do educador-amigo.

Observa-se que os dois grupos preferiram o termo "educador", em vez de "professor", para se referir ao profissional que atua diretamente com a criança pequena. Tal fato nos leva a concluir que os ingressantes de Pedagogia ainda não admitiam, em 2009, um professor atuando com crianças em creches e pré-escolas, nem "se viam" como futuros professores de crianças pequenas no momento em que fizeram as evocações.

Em março de 2009, início do primeiro ano de curso, o grupo de estudantes referiu-se ao termo professor, à imagem e ao trabalho tomando como referência o professor de crianças dos primeiros anos/séries do Ensino Fundamental. A profissão de professor da El obteve reconhecimento legal somente a partir da LDB/96. Dessa maneira, a referência de professor como profissional é a do professor dos anos/séries iniciais do Ensino Fundamental. Este resultado não causa estranhamento, visto que as RS são elaboradas com base nas experiências socioculturais e pessoais vivenciadas num contexto histórico objetivo. Os estudantes estiveram imersos em inúmeras situações, anteriormente ao ingresso no curso de Pedagogia, e provavelmente suas crenças sobre criança e professor de crianças têm como referência o professor de Ensino Fundamental, reconhecido socialmente como profissional do ensino, pois se entende que tem o quê ensinar. Na Educação Infantil, o senso-comum veicula que o professor faz diferente, mas não se sabe ao certo o que faz, nem como é adequado fazer; portanto, a denominação recaiu no termo "educador", como já mencionado. 
Sobre o questionário-carta, no que diz respeito à questão que solicitava aos estudantes o apontamento da preferência pelo campo de trabalho, a tendência verificada foi diversificada. Os alunos da UNESP enfatizaram as três alternativas: ser professor universitário, professor de creche e pré-escola e professor de pré-escola (nessa ordem). Embora o magistério na El não seja a primeira opção, tal possibilidade se encontrava presente entre os ingressantes de Pedagogia da UNESP, diferentemente dos estudantes da UFMS, que apontaram a preferência pela atuação em supervisão ou orientação, como professores das séries iniciais do Ensino Fundamental e em Educação Especial; no caso da última opção, cabe destacar que esta é uma área tradicionalmente bastante trabalhada e valorizada no curso de Pedagogia da UFMS. Os professores envolvidos com Educação Especial e Educação Social são aqueles com os quais os alunos simpatizam bastante; são também esses professores que ministram aulas das primeiras disciplinas com as quais os alunos têm contato, além do fato de, até o ano de 2009 , serem essas as duas únicas áreas temáticas efetivamente estudadas e discutidas fora do espaço formal da sala de aula, o que pode ter influenciado a resposta nesse contexto. Por fim, podemos inferir que a El não se constitui preferencial como campo de trabalho no futuro.

Por um lado, ao serem solicitados a se posicionar sobre a motivação para atuação futura na El, os dois grupos pareceram motivados. A razão mais assinalada estava relacionada ao fato de se ficar próximo da criança pequena e poder ajudá-la, o que nós inferimos como uma visão assistencialista da futura profissão e preconceituosa da criança, visto que pode indicar a compreensão atual do trabalho na EI como maternagem e a própria criança como um ser incompleto. Por outro lado, pode indicar o sentimento altruísta que tem acompanhado a identidade do professor - trabalhar para o bem comum, a favor da emancipação do outro. Estes são aspectos a serem investigados nas próximas etapas da pesquisa longitudinal.

Sobre a minoria que respondeu não estar motivada para atuar na El, houve certa diferença entre os dois grupos; enquanto estudantes da UNESP enfatizaram a não identificação profissional e a falta de reconhecimento profissional como justificativa, os estudantes da UFMS mencionaram, além da falta de identificação profissional, a falta de preparo para o trabalho com crianças pequenas. Os resultados obtidos com essa pergunta, se confrontados aos resultados sobre a preferência pelo campo de trabalho, já discutida antes, revelam que os estudantes dos dois grupos ainda não optaram pela atuação como professor de creche e pré-escola, colocando em dúvida a motivação antes referida.
Ao serem inquiridos sobre a proximidade da profissão de professor de creche com outras profissões, a grande maioria de ambos os grupos respondeu que tal atividade está próxima do trabaIho de babá. A justificativa dos estudantes para tal entendimento de sua futura profissão se referenda na compreensão de que babás e professores têm a tarefa de atender às necessidades básicas da criança, o que nos reporta à motivação apontada antes - ajudar a criança. A mesma pergunta feita sobre o professor da pré-escola obteve resposta igual para os dois grupos de estudantes, sendo indicada como a profissão mais próxima à de professor do Ensino Fundamental, justificada pelo entendimento de que esse é o período do início da alfabetização escolar. Tal identificação pode se explicar pelo entendimento corrente de que o ensino para as primeiras idades deve focar a aprendizagem da escrita.

Nessas respostas temos presente a clássica dicotomia que envolve a El brasileira: a creche deve cuidar e, nesse sentido, a figura da babá é requisitada para exercer a maternagem no atendimento na creche brasileira ( 0 e 3 anos de idade), distanciando-se do professor com formação específica, enquanto a pré-escola deve educar. O cuidar comparece como suprimento das necessidades físicas, de saúde e algumas vezes afetivas, ao passo que o educar é visto como a escolarização precoce, com foco na alfabetização, a exemplo das rotinas e práticas próprias dos anos/séries iniciais do Ensino Fundamental. Ao serem perguntados sobre as tarefas da professora de creche, as atividades indicadas pelos dois grupos foram iguais, sendo as três recorrentes - dar carinho, brincar e organizar brincadeiras -, nessa ordem para os dois grupos. No que diz respeito às tarefas da professora de pré-escola, houve alguma discrepância nas indicações. Enquanto os alunos da UNESP entendem que as atividades prioritárias seriam ensinar a ler e escrever, organizar reuniões de pais, além de observar e avaliar as crianças, os alunos do UFMS indicam as tarefas atender crianças com necessidades especiais, organizar brincadeiras e, por último, ensinar a ler e escrever.

Os dados demonstrados anteriormente reforçam o apontado como NC das RS sobre o que él como é ser professora de crianças pequenas, além de caracterizarem uma cisão entre as tarefas de cuidar e educar na $\mathrm{El}$, atribuindo às creches $(0$ a 3 anos) as tarefas voltadas aos cuidados físicos, e às pré-escolas (4 a 5 anos) o trabalho educativo reduzido à preparação para os anos posteriores da escolarização obrigatória. Esses resultados impõem às etapas posteriores deste estudo a investigação das prováveis diferenças de RS sobre ser professora da creche e professora da pré-escola e suas tarefas, além de pesquisar se, no decorrer do processo formativo na universidade, essas RS se transformam ou se mantêm resistentes, reforçando-se. Há que 
se considerar as singularidades contextuais de cada grupo estudado, com destaque especial para a ênfase dada pelo curso de Pedagogia da UFMS à Educação Especial.

A teoria das RS nos ampara para afirmar que as conversas, as crenças, as experiências e as ações valorizadas num determinado grupo, numa determinada cultura, condicionam a elaboração das RS. As RS têm o papel de transformar o que é estranho e distante em algo próximo e familiar, o que nos possibilita compreender a "utilização" da referência de professor do Ensino Fundamental e suas tarefas para organizar a RS de professor da EI, com destaque ao professor da pré-escola e à imagem e tarefas da babá, para a professora da creche. Outros estudos recentes encontraram RS muito parecidas entre estudantes (GUIMARÃES, 2000; LIMA; FERNANDES; GONÇALVES, 2009; ENS; EYNG; GISI, 2009; HADDAD, 2009), o que exige não perder de vista que os dois grupos estão inseridos no contexto histórico-cultural brasileiro e se localizam em regiões com características sociais, políticas, econômicas e educacionais muito particulares, o que propicia experiências singulares aos sujeitos.

Resumindo, podemos afirmar que os estudantes das duas universidades - UNESP e UFMS têm perfis bastante parecidos, com exceção do fato de os ingressantes do curso de Pedagogia da UFMS serem cronologicamente um pouco mais velhos.

No que diz respeito à RS do que é/como é ser professora de crianças pequenas, os dois grupos não diferiram de forma muito discrepante, apresentando distanciamentos e aproximações, conforme os dados demonstraram. A RS de ambos os grupos sobre professora não contém elementos ainda para compor a natureza do trabalho pedagógico da/na El, da identidade da professora que deve atuar nesse segmento educacional. No entanto, cabe reafirmar que a RS sobre professora dos estudantes da UFMS se encontra ancorada em aspectos que se distanciam mais da imagem de professor veiculado pela legislação e pela literatura da área, do que a dos estudantes da UNESP.

\section{O que dizem os dados das entrevistas}

Acerca da entrevista realizada em novembro de 2010, selecionamos seis questões consideradas pertinentes à verificação se o curso de Pedagogia foi capaz de provocar alguma transformação/mudança sobre as RS de criança e de ser professora da Educação Infantil. Inquirimos cinco alunas da UFMS e dez alunas da UNESP (cinco do período vespertino e cinco do período noturno).
Ao serem questionadas se "quando escolheram fazer a Pedagogia pretendiam ser professoras de crianças pequenas", dentre as alunas da UFMS, duas disseram que não; no entanto, afirmaram que passaram a considerar essa possibilidade de atuação, com a passagem do tempo, atribuindo ao curso tal mudança de pensamento:

Não. Foi depois, quando a gente começou a estudar mesmo Educação Infantil que eu gostei e pretendo ficar mais na Educação Infantil. (UFMS, sujeito 1)

Não. Pequena não. Eu me interessava por séries inicias [...] eu não tinha vontade de trabalhar com criança pequena, era mais com criança maiorzinha... Aí depois quando eu entrei para o curso, e eu tenho uma sobrinha que tem dois anos, tenho contato com ela, com o curso e com os nenéns, fui aprendendo a gostar e hoje me identifico mais com a Educação Infantil do que com as séries iniciais. (UFMS, sujeito 3 )

No que diz respeito às estudantes da UNESP, nos dois grupos a maioria (sete alunas) afirmou que sim, que já pensava nessa possibilidade; das respostas negativas apenas uma aponta uma possibilidade de mudança de opinião devido à vivência no curso:

Sim, pequenas, infantil I e II. Eu acho que essa é uma fase gostosa, em que a criança acaba se apegando ao professor, acho que assim aquele conhecimento que você vai passar para a criança nesse período, acho que é o conhecimento que ela mais vai guardar ao longo dos tempos né, a primeira professora, é a que sempre, acho que é por ai. (UNESP - noturno, sujeito 4)

No primeiro momento não, optei mesmo por causa da gestão. Agora tanto faz, no decorrer do curso ser professor não vai ser uma coisa tão complexa e optaria pelo ensino infantil, perdi o medo. (UNESP - vespertino, sujeito 3)

Valle (2006, p. 180) assevera que

A escolha inicial e normalmente prematura de uma profissão - que na era moderna se torna cada vez menos definitiva, dependendo cada vez mais das flutuações do mercado e da extensa especialização das áreas profissionais - é apenas uma, dentre as muitas, que se sucedem na vida. Apesar disso, não podemos esquecer que essa escolha está relacionada com objetivos, nem sempre muito claros, que se quer perseguir, e com o grupo de referência no qual se pretende buscar prestígio, distinção, realização.

Segundo a mesma autora, a compreensão das escolhas individuais exige considerar as estruturas objetivas do campo profissional, assim como suas lógicas de funcionamento e de transformação. Valle (2006) pressupõe que a escolha profissional deriva da posição social dos pais (ligada que está à profissão 
que exercem), além de sua posição sociocultural e seus níveis de escolarização. Esses parâmetros orientam a projeção da escolarização dos filhos, delimitando assim as fronteiras das suas ambições profissionais. A família abre um determinado leque de possibilidades que se articulam às condições de vida profissional. Enfim, a autora afirma que a escolha profissional depende muito do arcabouço cultural e escolar que o aluno detém.

\section{A mesma autora ressalta ainda que}

Ao contrário do que revela o senso comum, o destino de uma pessoa não se prende somente às características próprias de sua personalidade disposição, inteligência, caráter, vocação, aptidão, dons e méritos pessoais, que podem ser cultivados de maneiras diversas -, mas depende principalmente do fato de ter nascido num determinado momento histórico e num certo ambiente sociocultural, definido por elementos estruturais bem precisos: de ordem econômica, política, educacional. Esses elementos pesam sobre as opções de cada um e acabam por prescrever o futuro no mais longo termo, orientando a escolha pessoal e exercendo forte influência sobre o itinerário profissional. (VALLE, 2006, p. 179).

Questionados sobre o que pensavam, naquela data (ano de 2010, final do segundo ano de curso), o que era ser professor de creche e pré-escola, obtivemos de todos os estudantes da UFMS o que nos parece a ideia de que esse é o profissional capaz de cuidar e educar:

Eu acho assim que é... pra mim eu entendo assim que não é só educar, mas é também assim cuidar delas, é ajudar elas... é assim a conhecer o mundo, a ter uma visão de mundo... a se desenvolver, ter mais autonomia. (UFMS, sujeito 2)

Os estudantes da UNESP do período vespertino apresentaram respostas que se encaixam em objetivos mais amplos da educação, como por exemplo: "formar o cidadão", "dar uma formação sólida", "tratar todos os alunos igualmente". Vale lembrar que são jargões comuns nos meios acadêmicos, reveladores de RS.

Ser professor é ser mais que responsável pela formação do cidadão porque os pais não têm tido tempo de educar seus filhos e confundem o trabaIho do professor com isso. Tem sido mais que apenas uma profissão, tem sido algo que forma o ser humano. (UNESP - vespertino, sujeito 2)

Com relação aos alunos do período noturno, dois se referiram à necessidade de a atividade ser prazerosa, um não soube responder, um indicou se identificar mais com o Ensino Fundamental e apenas um se ateve à especificidade da Educação Infantil, mas com a clara visão de cuidar e educar de forma cindida.
Olha, eu acho que ser professora de creche e de pré-escola, acho que assim, professora de creche de pequeninho mesmo, acho que professora de creche ta mais ligada a função de cuidado, porque são muito pequeninhos, estão crescendo e se desvinculando do ambiente familiar, se apegado na figura do professor, acho que é mais uma função de cuidado, uma coisa meio materna. Agora de pré-escola eu acho que já começa a preparar para os conhecimentos prévios, antes das crianças adentrarem no primeiro ano, Ensino Fundamental, acho que assim, eu vejo o professor pelo menos desta modalidade de ensino preparando mesmo para um pré-conhecimento, eu vejo assim. (UNESP - noturno, sujeito 1)

A análise das respostas revelou que ao final do segundo ano os respondentes já se utilizam dos jargões acadêmicos e demonstram uma visão maternal do trabalho da professora da Educação Infantil, desarticulando as funções - cuidados e educação. Há que se considerar que tais alunos ainda não tiveram contato com disciplinas do seu curso, cujo objeto é a prática profissional, o que acontecerá a partir de 2011.

Acerca da visão da criança, perguntamos aos alunos sobre a imagem que lhes vinha à cabeça quando pensavam em crianças, primeiro da creche e depois da pré-escola pública, em duas questões separadas. Numa turma da UNESP (vespertina) e na turma da UFMS, a mesma resposta que foi oferecida para a primeira questão foi oferecida à segunda, numa clara dificuldade de perceber a diferença, não só etária, nas crianças que encontrarão nesses diferentes segmentos da Educação Infantil. Acerca das características apontadas, as estudantes da UFMS foram unânimes em apontar que a criança da Educação Infantil pública é a "criança carente" de forma geral (material e afetiva):

São crianças carentes, pelo que eu observei na creche são crianças carentes... É... muitas vão lá porque a mãe tem mesmo que trabalhar, senão não iriam. Acho que é isso que eu vejo, crianças carentes mesmo... De tudo. Financeiramente, afetivamente, elas são... quando a gente entra na creche elas já vem... é isso que eu percebi. Particular eu não sei, porque eu não fui e não tenho ideia... (UFMS, sujeito 1)

São crianças que na maioria das vezes são de baixo poder aquisitivo... são crianças que não vão poder chegar lá e pedir uma coisa cara para eles comprarem, o professor tem que ter isso na cabeça, como é na escola pública esse tipo de clientela. Penso que na escola pública tem todo tipo e criança, criança é criança... Não existe uma diferença de uma criança para outra. (UFMS, sujeito 3 )

As estudantes da UNESP, do período vespertino, em algumas respostas de forma velada, também veem a criança da Educação Infantil pública como carente: 
Imagem da minha escola... crianças normais... crianças... crianças.... não muito ricas... crianças.... não sei...porque é da rede publica, não são crianças vindas de famílias ricas...são crianças normais... (foi hesitante.... parecia escolher as palavras ou não encontrá-las para dizer o que realmente pensava) (UNESP - noturno, sujeito 4)

As estudantes do período noturno apontam que imaginam uma "diversidade" de crianças, crianças entendidas como "normais":

Tanto na pública como na privada é de diversidade, que eu vou encontrar com crianças na parte de diversidade, na parte social, econômica, física, cultural. (UNESP - vespertino, sujeito 3)

Ao serem solicitadas a descreverem a criança que encontrariam no âmbito da creche e da pré-escola, as alunas do período noturno da UNESP mencionaram a criança de maneira genérica, sem distinção de faixa etária. Apenas uma das entrevistadas estabelece uma distinção entre a criança de creche e a de pré-escola, sendo esta última marcada por características que remetem à aprendizagem (curiosa, que tem vontade de aprender), enquanto que a criança de creche é aquela que precisa de cuidados e tem limitações.

Acho que na creche a criança é mais ativa porque ta crescendo e ta de repente dando os primeiros passos, aprendendo algumas coisinhas, criança ativa, acho que criança que precisa de cuidados que é muito importante, eu acho que por outro lado é criança que precisa de um pouco de limitações, acho que deve ser isso da creche. Agora da pré-escola eu vejo aquela criança curiosa, que tem vontade de aprender, pelo menos eu via isso, a criança participativa também e a criança também que se apega, a criança que tem a necessidade de apego, pelo menos eu vi que nossos alunos têm uma identificação muito forte com os professores do primeiro ano, da pré-escola. (UNESP - noturno, sujeito 1)

Entre as alunas do período vespertino, predomina a visão de criança carente, já apontada na questão anterior, bem como a não distinção entre as especificidades das faixas etárias.

Ambas têm as mesmas características (creche e pré-escola): crianças com.... ai, meu Deus... não quero cair no preconceito.... emocionalmente com problemas, crianças com dificuldades de se relacionar, porém crianças com vontade de aprender / ter contato, talvez aquilo que em casa não tenham. (UNESP - vespertino, sujeito 1)

No que diz respeito às alunas da UFMS, a visão de criança carente encontra-se em somente uma resposta; duas alunas afirmam que esperam encontrar crianças de todos os tipos e outras duas que são crianças "normais".
Acho que são várias né, que não tem que definir um padrão assim. Acho que tem vários tipos de crianças, desde aquelas que em casa tem assim tudo. $E$ aquelas também que às vezes vão sem se alimentar direito, crianças que não exercem mesmo o direito de criança como cidadã, acho que é isso... Eu acho que da creche (pensa um pouco) é uma criança geralmente pelo que eu vi assim crianças mais tranquilas, agora da pré-escola como não tenho, mas geralmente pelo que eu to vendo meu irmãozinho ir, geralmente na pré-escola são mais assim, dão um pouquinho mais trabalho, são mais briguentas, assim são mais até violentas, jogam as coisas um no outro. (UFMS, sujeito 4)

Os dados permitem antever uma variedade de ideias sobre a criança. Há uma certa percepção de que existem muitos modos de ser criança e de viver a etapa da infância, contudo ainda matizada pelo preconceito, pelo desconhecimento da criança tal qual ela é. Aparece nas falas o que é de domínio do senso-comum: creche, lugar de criança carente, com dificuldades emocionais e de aprendizagem e pobre. Local onde ainda não se admite a ocorrência de processos de desenvolvimento integral e de elaboração de conhecimentos pelas crianças atendidas. Na pré-escola percebe-se uma negligência dos respondentes a respeito do cuidado e uma ênfase na aprendizagem. Dados que demonstram o trabaIho de formação inicial a ser realizado por ambos os cursos de Pedagogia.

Acerca da possibilidade de o curso provocar mudanças, questionamos as estudantes se a sua compreensão de criança havia mudado depois do ingresso no curso de Pedagogia. Todos os estudantes da UFMS afirmaram a ocorrência de mudanças:

Mudou... Porque antes eu não entendia porque que a criança brincava, agora eu sei porque que ela brinca. Então quando eu vejo uma criança brincando, me vem todo o repertório, tudo que estudei, ai eu sei porque que ela brinca, porque que ela tá brincando, porque que briga... Então assim já muda meu jeito de ver, já a entendo mais, já entendo porque que ela faz tais coisas. Muitas vezes eu via a criança que brincava muito, criança que fazia birra, criança que chorava, criança que xingava, então eu já assim, agora eu começo a compreender melhor porque que ela faz tudo aquilo, as vezes eu não gostava, ou então entendia porque que eu sentia raiva, porque que eu não gostava, que já tomava raiva da criança, agora entendo porque. (UFMS, sujeito 2)

Quatro dentre as estudantes da UNESP, do período vespertino, também afirmam que sua compreensão de criança sofreu alteração desde sua inserção no curso de Pedagogia:

Mudou, porque agora eu vejo que todas as crianças tem sua particularidade e que devemos entender o seu mundo como ele é e não como alguém que não se enquadra no mundo adulto, diferente ou inferior. (UNESP - vespertino, sujeito 3) 
No entanto, entre três das estudantes do período noturno, as respostas mostraram que sua compreensão sobre criança continua a mesma. Duas entrevistadas relatam como evoluiu sua compreensão. Uma refere-se à criança como aquela que precisa de cuidado, de proteção, de uma aprendizagem efetiva, de afetividade. Outra entrevistada afirma que passou a perceber mais a criança, as ações, o desenvolvimento, antes superficial.

Acho que evoluiu um pouco na verdade, com tanta coisa que a gente vê no decorrer do curso, o professor tem muitas atribuições, muita responsabilidade, muita coisa que tem que desenvolver, então que acho que a criança acaba sendo uma extensão dentro dessa noção que a gente tem, que deve ter sobre o cuidado, o ensino e a aprendizagem dela, a importância desse ensino, dessa aprendizagem pra elas. Então eu acho que pelo menos eu vejo a criança como um ser que sobre, nossa tem muita responsabilidades por parte da gente que precisa de cuidado, que precisa de proteção que precisa de uma aprendizagem efetiva, de afetividade, eu vejo com respeito mesmo, com carinho. (UNESP noturno, sujeito 1 )

O curso ainda não imprimiu mudanças, mas podemos afirmar que o contexto acadêmico inspira novos olhares ou novas nuances ao antigo olhar sobre a criança, sobre o trabalho com ela, sem, contudo, provocar perigo às RS iniciais sobre criança e sobre o professor de crianças.

Outra questão lançada aos estudantes foi sobre os sentimentos que lhes vinham à mente quando pensavam em seu futuro como professores de creche e de pré-escola. As respostas oferecidas pelos estudantes da UFMS foram todas relacionadas a sensações positivas tais como alegria, paixão, satisfação, mas também foram citados sentimentos como preocupação com a responsabilidade a ser assumida.

Responsabilidade, acho que é responsabilidade principalmente. Porque você vai estar dando a base da educação... Eu sinto pra mim que eu tenho que ser responsável e isso gera preocupação. Um pouco de preocupação, porque eu sei que eu vou ser responsável por uma criança, então me preocupa bastante. (UFMS, sujeito 1)

Ah! Acho que paixão pelo que eu vou fazer, porque é algo que eu quero, então eu sinto uma satisfação de estar buscando, por que é algo que eu sempre quis... (UFMS, sujeito 3)

Com relação aos estudantes da UNESP do período noturno, as respostas a esta pergunta apontam para uma mistura de sensações: satisfação, realização por fazer algo que se gosta, tranquilidade, ansiedade, temor por não saber como será o trabalho com crianças pequenas, medo com relação à família e insatisfação relacionada à busca de meIhoria. É importante destacar que a palavra alegria é a que mais se repete, aparecendo na fala de três das cinco entrevistadas, o que revela um sentimento maternal e uma visão ainda ideal e romântica do trabalho com crianças, além de uma posição otimista perante a futura profissão.

Um sentimento de satisfação, de realização, de paciência também que a gente precisa, mas eu acho que assim, de satisfação mesmo de estar ali, de realização de fazer uma coisa que a gente gosta, basicamente isso. (UNESP, noturno, sujeito 1)

Ansiedade, alegrias e um pouco de temor também pra ver como que vai acontecer a espera, como vai ser a parte prática, eu na sala de aula dando aula pras crianças... (UNESP, noturno, sujeito 3)

Para as estudantes da UNESP, do período vespertino:

Sentimento de fazer diferente, de mudança, de contribuir, vontade de contribuir para que seja um pouco diferente (para creche e pré-escola). (UNESP, vespertino, sujeito 1)

Sinto bem, alegria de ser um professor, acho que é a área mais difícil de lidar porque as crianças são muito novinhas, tem que ter muito cuidado, os pais jogam as responsabilidades para o professor, tudo é na escola que se aprende. (UNESP, vespertino, sujeito 4).

Podemos inferir que as expectativas misturam compreensões preconceituosas e sentimentos de otimismo e satisfação emanados de uma visão ainda ideal da criança e do terreno da futura atuação profissional, além do desconhecimento do conteúdo do trabalho pedagógico com crianças na creche e na pré-escola.

\section{Palavras finais: reflexões (in)conclusivas e desafios futuros}

Em síntese, os estudantes da UNESP tendem à organização do NC de sua RS em torno da ideia-imagem do educador-profissional que ensina na escola com responsabilidade, autoridade, inteligência, amizade e respeito. Por sua vez, os estudantes da UFMS pareceram organizar o NC de sua RS em torno da ideia-imagem do educador-amigo. Observa-se que os dois grupos preferiram o termo "educador", no masculino, no lugar de "professor(a)", para se referir ao profissional que atua diretamente com a criança pequena, o que nos leva a concluir que os ingressantes de Pedagogia ainda não conseguiam admitir um professor(a) atuando com crianças em creches e pré-escolas.

Sendo assim, não encontramos, ainda, nesse grupo, as RS sobre PROFESSOR que indiquem elaborações sobre o que é/como é ser professora 
de crianças pequenas, bem como sobre a especificidade do trabalho pedagógico na El. Em ambos os segmentos, ao se referirem ao termo professor, os estudantes pesquisados associam-no à imagem e ao trabalho do professor de crianças do Ensino Fundamental, e as práticas educativas são aquelas próprias dos primeiros anos/séries desse nível de ensino.

Para Wallon (1979), à pré-escola cabe o papel de preparar a emancipação da criança, reduzir a influência exclusiva da família e promover o seu "encontro" com outras crianças da mesma idade. $\mathrm{O}$ autor esclarece que as relações a serem mantidas entre os pares de crianças e também com os adultos serão muito elementares, o que ocasiona ser a disciplina diferenciada da dos outros níveis escolares. É essa natureza educativa que preconiza o bem-estar da criança, sendo que, para tanto, exige-se que "as educadoras mantenham relações de ordem pessoal, directa, quase de natureza maternal". (WALLON, 1979, p. 208).

Desta forma, defendemos que a Educação Infantil necessita ser um espaço de mediação da inserção social e cultural das crianças ao mundo dos adultos, mas que tenha como foco a criança em si mesma, a diversidade de capacidades (intelectual, estética, motora, emocional etc.) e necessidades próprias dessa faixa etária. Assim, é instância específica com identidade e finalidade própria, finalidade essa de promoção da criança, de auxílio ao crescimento e desenvolvimento infantil, de aprendizagem, de construção de conhecimento, de formação integral de seus atores. Sendo assim, tem uma finalidade complementar e não substituta das funções que são e devem ser exercidas pela família (RODRIGUES, 2008).

Nesse sentido, a instituição formal de educação e cuidado tem seu papel e lugar assegurados na dinâmica social e principalmente no processo de desenvolvimento humano, não precisando e nem devendo incorporar de outras instituições o modelo das relações a serem estabelecidas em seu interior.

Os anos de formação inicial podem integrar o argumento anterior e, também, reconhecer a intencionalidade da atuação do professor, uma vez que é necessário ao profissional que atua diretamente com a criança, no desempenho de sua função, uma aproximação, mas também um distanciamento do cuidar materno instintivo, devido à especificidade de sua tarefa. Em outros termos, ao mesmo tempo em que se aproxima, o seu papel se distancia do de "mãe", ao articular as dimensões de cuidado e de educação necessárias nessa etapa da vida da criança. Essa aproximação e distanciamento são constantes na prática da Educação Infantil e elementos básicos na identidade de seus profissionais, uma vez que, ao integrar outros papéis, estão envoltos por inúmeras complexidades. (RODRIGUES, 2008).
Almeida (2006, p. 106) afirma que "não devem ser igualadas relações como a dos pares mãe-filho e professor-aluno, que são funcionalmente distintas". Para Wallon (1979), a cópia e reprodução dos modelos advindos da família não é adequada, uma vez que cada um desses grupos trará uma contribuição distinta ao desenvolvimento infantil. O mesmo autor ainda afirma que a educação formal é um campo privilegiado, cuja função é tratar da obra mais fundamental de uma sociedade: a educação das crianças. Também é essa a razão pela qual reafirmamos algo quase clichê: que não se pode deixar a Educação Infantil se "contaminar" por cunhos exclusivamente assistencialistas ou escolarizantes. Esse é outro aspecto a ser confrontado com as antigas crenças dos estudantes, nos momentos de reflexão, nos anos de formação inicial.

Segundo Almeida (2006), é da disposição de o professor estar voltado para seus educandos que dependerá a marca de sua contribuição ao desenvolvimento da criança que Ihe foi confiada, pois tanto na seleção dos saberes, quanto em sua transposição didática, o educando está sempre na dependência da competência e compromisso do educador.

Nesse sentido, toda expectativa despendida na atuação do profissional de Educação Infantil exige das práticas de formação inicial e continuada a criação de contextos significativos suficientemente capazes de fomentar o "pensar crítico", base e condição sine qua non para a formação da necessária identidade profissional de professor que atua junto às crianças pequenas no contexto da Educação Infantil.

Dessa forma, os resultados da pesquisa encontrados até o momento impõem às etapas posteriores deste estudo a investigação das prováveis diferenças de RS sobre ser professora da creche e professora da pré-escola e suas tarefas, além de pesquisar se, no decorrer do processo formativo na universidade, essas RS se transformam ou se mantêm resistentes, reforçando-se.

\section{Referências}

ABRIC, J. C. L-organization interne des représentations sociales: système central et système pèriphèrique. In: GUIMELLI, C. Structures et transformations des représentations sociales. Lausanne: Delachaux et Niestlé. 1994. p. 73-83.

ALMEIDA, L. R. de. Wallon e a educação. In: MAHONEY, A. A.; ALMEIDA, L. R. de. (Org.). Henri Wallon: psicologia e educação. 6. ed. São Paulo: Loyola, 2006. p. 71-87.

BAILLAUQUĖS, S. Trabalho das representações na formação dos professores. In: PAQUAY, L.; 
PERRENOUD, P.; ALTET, M.; CHARLIER, E. (Org.). Formando professores profissionais: quais estratégias? Quais competências? 2. ed. rev. Porto Alegre: Artmed, 2001. p. 37-54.

BARDIN, L. Análise de conteúdo. Lisboa: Edições 70, 1977.

BRASIL. Lei n 9394/96, de 20 de dezembro de 1996. Estabelece as diretrizes e bases da educação nacional. Diário Oficial da União, Brasília, 23 dez. 1996.

CAMPOS, M. M.; FÜLLGRAF, J.; WIGGERS, V. A. Qualidade da Educação Infantil brasileira: alguns resultados de pesquisa. Cadernos de Pesquisa, São Paulo, v. 36 , n. 127 , p. $87-128$, jan./abr. 2006. DOI: 10.1590/S0100-15742006000100005

CERISARAA. B.; CANDAL ROCHA, E. A.; SILVAFILHO, J. J. Educação Infantil: uma trajetória de pesquisa e indicações para a avaliação de contextos educativos. Zero a Seis - Revista Eletrônica, Florianópolis, n. 15, jan/jun. 2007.

CERISARA, A. B. A construção da identidade das profissionais de Educação Infantil: entre o feminino e o profissional. 1996. 184 f. Tese (Doutorado em Educação) - Faculdade de Educação, Universidade de São Paulo, São Paulo, 1996.

ENS, R. T.; EYNG, A. M.; GISI, M. L. Políticas de formação de professores e as representações de estudantes de Pedagogia e Biologia sobre o trabalho docente. NUANCES: estudos sobre educação, Presidente Prudente, v. 16, n. 17, p. 69-83, jan./dez. 2009.

GUIMARÃES, C. M. Representações Sociais e formação do professor pré-escolar. 2000. 330 f. Tese (Doutorado em Educação) - Faculdade de Filosofia e Ciências, Universidade Estadual Paulista, Marília, 2000.

. (Org.). Perspectivas para Educação Infantil. Araraquara: Junqueira \& Marin, 2005.

HADDAD, L. Professora de El? Em busca do núcleo central da representação sociais a partir da análise das evocações livres. NUANCES: estudos sobre Educação, Presidente Prudente, v. 16, n. 17, p. 85-104, jan./dez. 2009.

LIMA, R. C. P.; FERNANDES, M. C. S. G.; GONÇALVES, M. F. C. Representações sociais de alunas de Pedagogia sobre o trabalho docente: estágio e experiência. NUANCES: estudos sobre educação, Presidente Prudente, v. 16, n. 17, p. 53-68, jan./dez. 2009.

MACHADO, M. L. A. Criança pequena, Educação Infantil e formação dos profissionais. Perspectiva, Florianópolis, v. 17, n. Especial, p. 85-98, jul./dez. 1999.

. Desafios iminentes para projetos de formação de profissionais para El. Cadernos de Pesquisa, São Paulo, n. 110, p. 191-202, jul. 2000. DOI: 10.1590/ S0100-15742000000200009
MOSCOVICl, S. A representação social da psicanálise. Tradução por Álvaro Cabral. Rio de Janeiro: Zahar, 1978.

On social representations. In: FORGAS, J. $\overline{P .(E d .)}$. Social cognition: perspectives on everyday understanding. London: Academic Press, 1981. p. 181209.

Representações sociais: investigações em Psicologia Social. Petrópolis, RJ: Vozes. 2003.

MOSCOVICI, S.; HEWSTEONE, M. De la science au sens commun. In: S. MOSCOVICI (Ed.). Psychologie Sociale. Paris: PUF, 1984a. p. 539-566.

RODRIGUES, S. A. Expressividade e emoções na primeira infância: um estudo sobre a interação criança-criança na perspectiva walloniana. 2008. 110 f. Dissertação (Mestrado em Educação) - Faculdade de Ciências e Tecnologia, Universidade Estadual Paulista, Presidente Prudente.

VALLE, I. R. Carreira do magistério: uma escolha profissional deliberada? Revista Brasileira de Estudos Pedagógicos, Brasília, v. 87, n. 216, p. 178187, maio/ago. 2006.

VERGĖS, P. Ensemble de Programmes Permettant L'annalyse des Evocations - EVOC 2002. Manuel, version 5 april 2002

WALLON, H. Psicologia e educação da criança. Lisboa: Editorial Vega, 1979.

Recebido em 08/05/2011

Versão final recebida em 04/10/2011

Aceito em 04/10/2011 